\title{
Os dispositivos de dominação neocolonial e o ocaso das humanidades
}

The devices of neocolonial domination and the dusk of the humanities

\section{cristiano cәpovilla*}

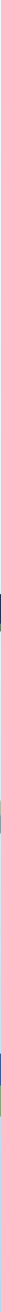




\section{RESUMO}

Ao reivindicar a retirada de financiamento das áreas de ciências humanas, o presidente explicita o sistema de ideias que legitimam a racionalidade técnica do poder econômico capitalista, bem como as formas de consciência social específicas da fase neoliberal contemporânea. O objetivo é eliminar qualquer pressuposto - filosófico, artístico, histórico - que embase um discurso autônomo, para além das determinações técnicas dos grandes centros do poder global. Ao eliminar a possibilidade de um discurso próprio, capaz de refletir sobre seus próprios fundamentos, pretende-se eternizar os dispositivos de dominação neocolonial.

Palavras-chave: Humanidades; Neocolonialismo; Humanismo; Comunidade nacional; Formação

\section{ABSTRACT}

When he requests to defund the social sciences, the president Bolsonaro unveils the system of ideas that valides the technical rationality of capitalist economical power, as well as the specific social awareness of this contemporary neoliberal phase. His aim is to eliminate any - philosophical, artistic, historical - assumptions that gives power to an autonomous discourse, beyond technical determinations of large global power centres. Eliminating the possibility of an unique discourse, capable of meditating on its own structure, there is the wish to make neocolonial domination devices eternal.

Keywords: Humanities; Neocolonialism; Humanism; National community; Formation

Apenas quatro meses após tomar posse, o presidente Jair Bolsonaro divulgou em rede oficial que:

O ministro da Educação @abrahamWeinT estuda descentralizar investimento em faculdades de Filosofia e Sociologia (humanas). Alunos já matriculados não serão afetados. O objetivo é focar em áreas que gerem retorno imediato ao contribuinte, como: veterinária, engenharia e medicina (BOLSONARO, 2019).

O propósito de gerar "retorno imediato" deslocando investimentos de "Filosofia e Sociologia (humanas)" é de uma vulgaridade exemplar. A completa incapacidade do presidente da República em desenvolver uma argumentação minimamente persuasiva o obriga a utilizar um raciocínio tosco que, por um lado, se não favorece a eminência que se espera do ocupante do mais alto posto da República, por outro, pelo menos proporciona aos interlocutores a demonstração do seu visível interesse, além de expor os elementos capciosos que estão por trás da sua fala. 
Sabemos que, em cumprimento a determinações ideológicas típicas dos enunciados das classes dominantes, a lógica subjacente aos discursos possui sentido trocado ou invertido. No caso em questão, é possível desvendar todo um novelo ideológico, no qual se dissimula e movimenta aquela pulsão de morte voltada contra as humanidades que tanto norteia o novo mandatário do país. Ao reivindicar a retirada de financiamento das áreas de humanas - que, por sinal, são as que recebem os menores investimentos quando comparadas às outras áreas acadêmicas ${ }^{1}$-, em tese favorecendo "áreas que gerem retorno imediato", o presidente explicita o sistema de ideias que legitimam a racionalidade técnica do poder econômico capitalista e suas formas de consciência social, ambas específicas da fase neoliberal contemporânea.

O recurso linguístico a termos como utilidade, retorno imediato, vantagem e serventia só pode ser aplicado em um universo léxico no qual os elementos estão em relação de subalternidade com uma totalidade técnica, isto é, convêm a algo que funciona apenas como meio e não como finalidade. O conjunto da educação superior, por definição, jamais pode se constituir unicamente por uma natureza conceitual intermediária. Mas por que, então, para nossa nova elite dirigente, a educação superior executaria apenas atividades-meio, imediatas, não tratando das finalidades, dos objetivos maiores, históricos, da comunidade nacional?

Essa contraversão na ordem dos elementos conceituais é sustentada por uma visão estratégica de despolitização social que se baseia no entendimento unilateral da compreensão. O fio condutor da implantação compulsória dessas ideias reside na expulsão da tradição do pensamento humanista do campo do conhecimento científico e no consequente descrédito das noções de comunidade e formação. O objetivo é eliminar qualquer pressuposto - filosófico, artístico, histórico - que embase a elaboração e o desenvolvimento de um discurso para além das determinações técnicas dos grandes centros do poder global, cuja pretensão é implantar a autorreprodutibilidade dos dispositivos de dominação de caráter neocolonial. Portanto, no atual ataque às humanidades, há duas ordens de questões em jogo: uma teórica outra política.

\section{DESPOTISMO ESCLARECIDO E AUTOCRACIA RACIONAL}

Do ponto de vista teórico, as críticas mais contundentes às humanidades têm origem ainda na Europa dos séculos XVIII e XIX e se estabeleceram na forma de diversas tentativas de transpor mecanicamente métodos, técnicas e linguagem das ciências formais e naturais para a tradição do humanismo renascentista. O deslocamento e reinterpretação de importantes noções filosóficas, como a do conhecimento, que passou a ficar restrito ao âmbito da experiência empírica possível, da objetividade, que se moveu em direção à mensuração experimental, e a tentativa de submeter o todo da

\footnotetext{
Segundo o Censo da educação superior de 2017, do CNPq e da Capes, na graduação apenas $2 \%$ dos alunos das Ifes (instituições federais de ensino superior) cursam Filosofia ou Sociologia. No mestrado e doutorado, apenas 2,5\% dos 66 programas das Ifes são das duas áreas. No que se refere ao pagamento de bolsas, a área de ciências humanas representa apenas 1,4\% dos gastos do CNPq, sendo que a Filosofia fica com apenas $0,7 \%$. Já as engenharias recebem cerca de $20 \%$ do valor total distribuído pelo órgão.
} 
linguagem às formulações lógico-matemáticas constituem partes expressivas dessas transposições metodológicas e cientificistas.

A ascensão da burguesia ao centro do poder político configurou o espírito do tempo segundo o qual algumas ciências particulares deveriam se estabelecer como paradigma de todos os saberes, precisando, para tanto, afastar os pressupostos filosóficos - também chamados de "metafísicos" - e a tradição humanista - principalmente o comunitarismo e a formação do homo universalis. As novas características dos antigos conceitos filosóficos deveriam, a partir daquele momento, ser iluminadas pelo otimismo subjetivo e individualista burguês, refletindo sua hegemonia política e social sobre o todo do saber humano. A especialização baseada no sucesso da física e na exatidão da matemática se casava com o ascendente liberalismo burguês, forjando uma simbiose teórica e política consistente e adequada à expansão do mercado mundial capitalista.

Assim como o poder político se legitima através de uma legislação jurídica que normaliza as relações entre as classes subalternas e dominantes, constrangendo a luta de classes ao escopo das instituições vigentes, também o domínio metodológico e cientificista dos saberes possui sua própria legislação epistemológica, que procura padronizar suas pretensões de universalidade reprimindo outros pressupostos que atuam sobre o conjunto das compreensões humanas. Essas novas leis do conhecimento se fundamentam no sucesso preditivo das ciências naturais e formais e na pretensão de um deslocamento mecânico dos métodos, ferramentas técnicas, aparatos práticos e linguagens oriundas dessas ciências particulares em direção às humanidades. Haveria portanto, segundo essa concepção, uma régua objetiva e exógena para mensurar a eficácia dos saberes.

Essa atitude cognoscente acabou por acarretar uma ameaça universalizante e excludente, uma vez que a jurisdição epistêmica sobre o conjunto da racionalidade possui a intenção de ser supressiva, difundindo a metodologia cientificista como a única legítima a discursar sobre o conhecimento e a verdade. A consideração segundo a qual a dignidade do conhecer só começa a partir do horizonte instalado pelo Iluminismo (Aufklärung) termina por concluir que toda a história pregressa do saber e dos povos não submetidos a essa legislação estaria fora do contrato civilizatório, numa espécie de estado de natureza do conhecimento. Desse modo se construiu a conjunção entre o despotismo esclarecido do absolutismo e a autocracia racional do liberalismo.

Isso explica muito da associação entre o cientificismo positivista do século XIX e o liberalismo colonialista. A conexão ideológica entre o "século das luzes" (século XVIII) e o "longo século XIX" — nos dizeres de Hobsbawm ${ }^{2}$ — demostrou todo o risco de se adotar um único critério universal, válido por si mesmo, abarcando todos os tempos e lugares, tal qual um axioma matemático ou lei da física, para mensurar o desenvolvimento cultural de comunidades com universos de discurso tão diferentes.

2 Para a historiadora Maria Fernanda Rollo, Hobsbawm, ao escrever a trilogia A era das revoluções (The Age of Revolution ), A era do capital (The Age of Capital) e A era dos impérios (The Age of Empire), completava a análise do "longo século XIX" (2012, p.120). 
A ascensão da burguesia

ao centro do poder político

configurou o espírito do

tempo segundo o qual

algumas ciências particulares

deveriam se estabelecer como

paradigma de todos os saberes,

precisando, para tanto, afastar

os pressupostos filosóficos

- também chamados de

"metafísicos" - e a tradição

humanista

Toda expansão liberal-colonialista do século XIX se estribou nessa associação política, econômica e científica que opõe a civilização racional aos bárbaros irracionais (LOSURDO, 2006).

A questão filosófica que se coloca é a de saber quais condições tornariam possíveis escolhas objetivas e neutras dos métodos das ciências naturais em detrimento de um saber próprio das humanidades. Existiria realmente um ponto de Arquimedes a partir do qual pudéssemos mover o todo do conhecimento e mensurar o valor de suas distintas dimensões, avaliando aquelas como superiores e estas como inferiores? Ou estaria essa régua contida na própria ideologia que se pretende objetiva e neutra? Ora, fica evidente que a transferência dos mecanismos de objetividade da física e de neutralidade da linguagem matemática para as humanidades é que constitui o horizonte de interpretação do cientificismo iluminopositivista.

Ocorre que esse ponto de Arquimedes do saber cientificista se mostra ilusório, pois perante a milenar filosofia também ele é pressuposto, isto é, do mesmo modo está inscrito na estrutura da compreensão e interpretação dos sujeitos histórico-sociais. A pretensão cientificista de fornecer ideias objetivas e neutras, para além de qualquer horizonte de significação histórica e social, é ela mesma um elemento do horizonte de interpretação histórico-social. A mesma inferência vale para a crítica da naturalização das leis do capital. A compreensão apropriada dos desafios das humanidades deve levar em consideração algo da posição no tempo e lugar e da visão de mundo do intérprete, e, por esses meios, escutar o que a própria cultura tem a nos dizer, sem desconsiderar a constituição do seu saber construído no horizonte de uma tradição de pensamento. 
Nesta outra compreensão, portanto, seria plenamente legítimo aceitar o conhecimento e a verdade para além da legislação epistêmica do Esclarecimento e da justificação científica positiva, uma vez que o fenômeno da compreensão está presente em todas as referências humanas, inclusive nas próprias ciências naturais e formais, não podendo, assim, ser reduzido a uma metodologia particular. Essa resistência em não transformar o todo da compreensão em objeto de ciências particulares se baseia na aceitação de que as experiências de verdade ultrapassam o domínio da simples metodologia científica. O questionamento acerca das legitimações metodológicas e epistêmicas do próprio saber e o desafio de romper os ditames do entendimento positivista são as consequências necessárias dessa posição de resistência teórica e política a uma globalização unilateral do conhecimento.

Não se trata aqui, obviamente, de contestar a validade das ciências físicas e matemáticas, que sempre trouxeram grandes contribuições ao conhecimento humano, mas de salvaguardá-las em seus valores intrínsecos, não as confundindo com os interesses, usos e manipulações que o sistema econômico capitalista fez prevalecer na modernidade. Essa tentativa de expansão ideológica das ciências naturais e formais para além de si mesmas, numa espécie de controle do todo pelas partes, foi acompanhada de outro fenômeno: a colonização indevida dessas mesmas ciências por concepções do pensamento subjetivista e relativista, que subverteram os métodos e desrespeitaram as regras estabelecidas pelas comunidades acadêmicas.

Ao tentar unificar o todo do conhecimento sob uma mesma legislação epistêmica específica, externa ao conteúdo próprio e essencial da compreensão, a burguesia cindiu ainda mais a racionalidade, permitindo que interesses exógenos e a-históricos prevalecessem sobre a complexidade lógica inerente à cognição humana. O entendimento que provoca a cisão, inviabilizando a razão como totalidade de contrários, é a causa da morte da própria razão, pois, por definição, a racionalidade não se pode restringir a uma parte de si própria. Ela só tem existência real (isto é, só se realiza) "como integrante de uma totalidade que a subsume, conferindo-lhe sentido e função" (ABDALLA, 2019).

\section{HUMANISMO E CIÊNCIAS HUMANAS}

Por outro lado, a conturbada relação entre humanismo e ciências humanas implica, antes de tudo, explicitar alguns pressupostos necessários para a abordagem dessa questão. Como sabemos, o adjetivo humanas associado a ciências implica a localização desse saber no campo da epistemologia. Atualmente, todo endereço do saber acadêmico ocidental é designado pela jurisdição do conhecimento científico. A epistemologia ou teoria da ciência define a legislação e a taxonomia desse campo do saber humano. Assim, falar em ciências humanas já nos posiciona frente às questões determinadas pela ciência positiva moderna. Por esse raciocínio, relacionar humanismo a ciências humanas pressupõe considerá-las sob a ótica da epis- 
temologia, explicando o papel específico de cada uma dentro do conjunto maior do conhecimento científico.

Nesse sentido, o filósofo Ivan Domingues é claro na distinção que propõe ao defender que o século XIX seria a pré-história das ciências humanas, localizando o humanismo nesse tempo anterior, pregresso, passado. Para ele, só há sentido em falar de ciências humanas se fizermos referência ao século XX, e "no interior dos paradigmas vigentes na atualidade" (DOMINGUES, 2004, p.I6). Considera que, ao discursar sobre as ciências humanas, estamos condicionados pelo paradigma científico da modernidade, que localiza nos pressupostos da positividade iluminista e na aurora do mundo contemporâneo a instauração da ciência sociológica, centrada fundamentalmente na capacidade de explicação das teorias. Portanto, seria no horizonte de significados da discussão epistemológica atual que deveríamos abordar as ciências humanas. Daí porque epistemologia e ciências humanas seriam termos indissociáveis.

Se, de fato, for como expõe Domingues, então as próprias ciências humanas já teriam nascido sob a sujeição aos métodos, técnicas e linguagens transpostas da física e da matemática, tal qual foi pensado e construído pelo positivismo dezenovista. Ao adjetivar a ciência de humana ou social, desloca-se o que deveria ser o centro para um simples atributo, conexo e subordinado a algo exógeno, exterior, objetivo e neutro. Desse modo, o antigo humanismo estaria situado para além das fronteiras desse saber, como uma espécie de crença antiga, semibárbara, aquém do saber contemporâneo e civilizado.

Entretanto, o próprio Domingues não aposta todas as fichas na alternativa acima, dado que, ao discorrer sobre os fundadores das ciências humanas contemporâneas, reconhece que o problema da diferença de conteúdo entre eles "não é exatamente a lógica ou a epistemologia, mas a metafísica ou ontologia, em cuja origem vamos encontrar o velho problema do uno e do múltiplo". (DOMINGUES, 2004, p.I7I8). Ora, temos aqui a confissão de que, mesmo dentro do paradigma epistemológico que se pretende autônomo, há a existência de uma tradição de discurso cujo sentido milenar ainda se faz valer enquanto pressuposto do conhecimento.

É justamente na impossibilidade de escapar dos pressupostos ontológicos do compreender que reside a abertura para tratar das ciências humanas mesmo para além dos paradigmas epistemológicos positivos contemporâneos. Em face de tal constatação, pergunta-se: quais as condições práticas e teóricas que levaram as ciências humanas a se considerarem autônomas e particulares frente a uma tradição humanista que já existia e se fazia valer enquanto conhecimento e compreensão da sociedade?

Humanismo é um termo relativo ao amplo movimento renascentista europeu, que compreende o período transitório entre Baixa Idade Média e início da época Moderna (séculos XIV a XVI). Surgido provavelmente na Itália, colocava o humano e o seu mundo como o centro e referência de todas as coisas existentes no Universo. A filosofia, as artes e as ciências passavam a vislumbrar uma atividade intelectual renova- 
da, na medida em que voltaram a interessar-se pelos autores da Antiguidade clássica greco-romana. Houve uma interpretação do passado como condição necessária para compreender a vida da época.

A origem do termo humanismo provém da antiga palavra latina humanitas e remonta ao que os romanos cultivavam como uma qualidade essencial da vida: o ser parte da comunidade política, civis romanus. Cícero ${ }^{3}$ usou humanitas para descrever a formação dos cidadãos romanos, que, segundo ele, deveriam ser educados para se tornar oradores, isto é, fazer uso público da palavra, além de praticar um conjunto de virtudes e valores adequados para uma vida ativa na esfera comunitária. Para Cícero, humanitas não era uma doutrina formal, mas um complexo ordenado de valores, um pensamento para a ação. Afirmava a importância do humano como um ser que precisa ser cultivado na moderação do seu universo moral. Os cidadãos que praticavam humanitas ficavam confiantes do seu valor, corteses com os outros, decentes em suas condutas comunitárias e ativos em seus papeis políticos.

Foi Petrarca ${ }^{4}$, ao traduzir as cartas de Cícero, que trouxe o termo humanitas do antigo latim para a Renascença. Já como humanismo, o termo ganha uma nova amplitude, expressando a importância conferida ao cultivo da linguagem. Era através do domínio linguístico que os costumes comunitários deveriam ser substancializados na forma da cultura. As artes e as disciplinas associadas ao uso público e comunitário da palavra ganharam um novo ânimo. Os humanistas usaram seus ideais retóricos e dialéticos para atacar a filosofia escolástica e a posição central dada à lógica. Alegavam que a formação abstrata da lógica afastava o homem da sua condição prática, mantendo uma perspectiva contemplativa perante a necessidade de se conhecer a vida real.

Os humanistas, ao oporem a vida prática à contemplativa, retomam e atualizam em um novo patamar, por um lado, a querela medieval dos universais, e, por outro, o antigo debate entre Platão (428/427 a.C. - 348/347 a.C) e Aristóteles (384 a.C - 322 a.C) acerca da distinção entre a episteme theoretike - mais afeita a um saber matemático, formal e contemplativo - e a phronésis - um saber prático, mais adequado à práxis, ético-político e histórico. Os humanistas sustentavam o realismo contra o nominalismo, a vida ativa em detrimento da contemplativa.

O humanismo das humanidades oferece um campo particularmente fértil para esse trabalho de resistência ao predomínio positivo da metodologia cientificista, e de oposição ao individualismo anticomunitário. Isso ocorre porque partilha formas de experiências e compreensões que estão além do controle definido pelos interesses imediatos do capital, como, por exemplo, a experiência do conhecimento da filosofia,

3 Marco Túlio Cícero (106 a.C.-43 a.C.). Filósofo e político romano. Apresentou aos romanos as escolas da filosofia grega e criou um vocabulário filosófico em latim, distinguindo-se como linguista, tradutor e filósofo.

4 Francesco Petrarca (1304-1374). Intelectual, poeta e humanista italiano. Tornou-se um dos primeiros a redescobrir o conhecimento da Roma antiga e da Grécia antiga. Entre outras realizações, participou da primeira tradução latina de Homero (928 a.C - 898 a.C), e em 1345 descobriu pessoalmente uma inédita coleção de cartas de Cícero. 


\section{Para Hegel (1770-1831), ao adquirir formação somos levados aos interesses teóricos, pois toda ação prática é também tarefa do espírito, isto é, da cultura, não havendo separação absoluta entre ambos}

da arte e da própria história. São modos de compreensão cujas experiências de verdade não podem ser verificadas pelos meios metodológicos particulares da ciência positiva. Somente através do aprofundamento do fenômeno da compreensão, da prática, é que se dará cabo a essa tarefa do pensamento.

Podemos citar nesse contexto a abordagem filosófica e hermenêutica do pensador alemão Hans-Georg Gadamer (1900-2002), que em sua obra Verdade e método propõe, entre outras questões, um resgate dos conceitos humanistas. Para ele, os saberes que hoje são tratados na forma de objetos de um sujeito epistêmico abstrato sempre existiram como componente básico da vida social e histórica. Sua abordagem pretende trazer à tona não um problema de metodologia específica, de delimitação de objetos das ciências humanas, mas de ontologia, isto é, das condições que tornam possível a própria universalidade da compreensão. Ambos, sociedade e história, formam o campo linguístico-ontológico sobre o qual se debruça a hermenêutica da compreensão. Sua meta é abordar os problemas das ciências humanas pela ótica da filosofia.

Para a hermenêutica filosófica a compreensão e a interpretação não são um problema específico das ciências. "Compreender e interpretar textos não é um expediente reservado apenas à ciência, mas pertence claramente ao todo da experiência do homem no mundo" (GADAMER, 20II, p. 29). Subjaz a essa ideia o juízo de que a compreensão, ao contrário do que pretende a particularidade epistemológica, seria um constitutivo fundamental do ser histórico-social. A compreensão não é apenas um modo de comportamento do sujeito epistêmico, pois envolve discernimentos e verdades relacionados com uma tradição de pensamento. Prospectar conceitos do humanismo que ainda subsistem e atuam nas ciências humanas e sociais é um dos objetivos da sua hermenêutica filosófica.

\section{FORMAÇ̃̃ E COMUNIDADE}

Um dos conceitos oriundos do humanismo é o de formação, até hoje usado nas ciências humanas e sociais. Formatio era como os antigos romanos chamaram a paideia grega. No dizer clássico de Jaeger (200I, p. I4):

O princípio espiritual dos gregos não é o individualismo, mas o "humanismo", para usar a palavra no seu sentido clássico e originário. Humanismo 
vem de humanitas. Significou a educação do homem de acordo com a verdadeira forma humana, com o seu autêntico ser. Tal é a genuína paideia grega, considerada modelo por um homem de Estado romano.

Mais tarde, os idealistas alemães chamaram-na de Bildung e atribuíram-lhe um valor conceitual equivalente. Para Hegel (I770-I83I), ao adquirir formação somos levados aos interesses teóricos, pois toda ação prática é também tarefa do espírito, isto é, da cultura, não havendo separação absoluta entre ambos. Desse modo, cada indivíduo real, empírico e particular, se eleva no reino da cultura e do espírito através do idioma, dos costumes e das instituições do seu povo. Esses elementos fornecem a matéria-prima de que os indivíduos devem se apropriar ao se relacionarem com o mundo. Portanto, o indivíduo, ao se descobrir povo e voltar a si, compreende que a própria existência particular é coletiva e histórica.

A formação não é uma propriedade individual, mas pertence substancialmente à comunidade. Em um mundo formado humanamente de costumes, instituições e linguagem, estamos sempre a caminho da formação das nossas finalidades. Portanto, estamos diante de um conceito que não diz respeito somente ao aspecto teórico, mas demonstra também possuir um caráter ético, político e comunitário, uma vez que implica sempre a necessidade de abertura aos outros e aos diferentes saberes. A finalidade da formação é a abertura às várias dimensões do humano.

Ao destacar o caráter prático da formação, como trabalho de elevar-se ao universal, Hegel expõe a determinação fundamental do espírito histórico de uma comunidade, a saber, a de reconhecer-se a si próprio no ser-outro e, com isso, reconciliar-se consigo mesmo. A relação dialética entre o particular e o universal é aqui demonstrada como a mediação necessária entre ambos: entregar-se ao sentido universal imanente no particular é, ao mesmo tempo, saber limitar-se. Isto quer dizer que tornar o universal concreto, como sentido da ação ordinária, logo particular, é fazer-lhe seu. Nesse caso, o particular da ação não será nenhuma limitação e, ao mesmo tempo, o universal existirá enquanto histórico. A formação, portanto, não é apenas o alheamento, mas também o retorno a si mesmo. É o processo que realiza a elevação histórica do espírito ao sentido universal, mas é também o elemento onde se move aquele que se formou.

O sentido universal é, pois, uma totalidade de contrários, onde as diferenças, ao invés de impedirem o todo, possibilitam-no, uma vez que não poderá haver a totalidade com a exclusão do diferente. A questão da formação nos remete a pensar em uma experiência de abertura mais ampla, amplitude ao outro, ao ser, ao fenômeno da arte, ao passado que se faz presente em seu devir. Daí o sentido universal e comunitário das finalidades. As ciências particulares também aparecem, compondo o elemento mediador entre o alheamento e o retorno a si mesmo, isto é, também elas se movimentam na formação.

Há, nessa conclamação pela formação multidimensional do humano, um chamado irrecusável a nos conhecermos como comunidade, cultura e coletividade linguísti- 
ca, em suma, a compreendermos a importância de confeccionar um sentido profundo para a nossa sociedade, matéria-prima original sobre a qual devemos erguer nosso próprio modo de pensar, captando o que está inscrito no ethos da nossa formação histórica. É um movimento que deve dirigir a nós mesmos o questionamento da nossa própria indagação filosófica.

Essa transmutação do pensamento de nós próprios envolve também uma efetividade política que transcende o debate metodológico e se abriga no domínio da práxis, isto é, no campo da liberdade de ação, da independência coletiva e da autonomia das ideias. Ao colocar o pensar sobre a própria comunidade como centro, desenvolvemos as condições basilares para a autorregulação das finalidades, movimento precípuo de atribuição de sentido a qualquer projeto compatível com os anseios dos cidadãos de uma comunidade nacional soberana. Pensar e agir são duas dimensões da formação coletiva, da conversão do país e dos cidadãos a eles próprios.

\section{O NEOCOLONIALISMO E A DIVISÃO DO TRABALHO E DO SABER}

Do ponto de vista político, o ataque do governo federal às humanidades não é um fato isolado, mas expressão local de um fenômeno internacional associado ao crescimento de forças de ultradireita ao redor do mundo. Isto ocorre num quadro mundial complexo e intrincado de transformações do cenário geopolítico, tendo por pano de fundo a persistente crise do neoliberalismo e seus reflexos nas questões nacionais.

Devemos observar também que o cenário global é composto de intensa luta em torno do reordenamento do sistema de poder, ao mesmo tempo que ocorrem profundas transformações do processo produtivo decorrentes das inovações da chamada Quarta Revolução Tecnológica. O discurso técnico, consequentemente, volta a entrar em cena como existente per si. A luta em torno do poder político e do conhecimento produtivo, somadas as medidas de austeridade fiscal que beneficiam o rentismo especulativo, têm ampliado o fosso entre o capital e o trabalho, raiz fundamental de todas as cisões no mundo (CAPOVILLA, 2019, p. 267-268).

Nesse contexto de disputa, as potências imperialistas se movimentam tanto para conter a emergência de novos polos de poder quanto para subjugar as outras nações aos ditames da divisão internacional do trabalho e do saber. Reservam ao Brasil, no que diz respeito ao trabalho e emprego, somente uma indústria de baixa produtividade, rudimentar, poluente, predatória, e uma empregabilidade precarizada, sem direitos e com baixos salários. Nessa composição, os dispositivos de dominação neocolonial advogam um sistema educacional restrito, unilateral, unidimensional, em que os cidadãos deverão ser capacitados numa única dimensão: a técnica!

Ao atacar as humanidades, os novos mandatários do país querem legar às futuras gerações o esquecimento definitivo das questões referentes à perspectiva ética, estética, política, filosófica e histórica. Estes não devem ser considerados saberes 
Os dispositivos de

dominação neocolonial

advogam um sistema

educacional restrito,

unilateral, unidimensional,

em que os cidadãos deverão

ser capacitados numa única

dimensão: a técnica!

relevantes. Corremos o sério risco de perder a capacidade coletiva e comunitária de designar a nós mesmos a incumbência de determinar a finalidade dos nossos destinos enquanto nação. Trata-se, portanto, de um indeferimento político ao nosso futuro coletivo.

Fica claro que o discurso dessa nova extrema-direita expressa a exacerbação de um falso nacionalismo, um engodo construído em laboratórios exógenos com fartos recursos materiais, ideológicos e midiáticos, fazendo intensa guerra digital assimétrica. A massiva distribuição de fake news e factoides e o uso das redes sociais contribuíram tanto para a vitória eleitoral nas urnas quanto para a atual sustentação do governo. A pregação anti-humanista aparece de forma clara nas mensagens moralistas com fortes traços inquisitoriais, fazendo da intolerância e do ódio contra os trabalhadores, a esquerda, os negros, os índios e as orientações sexuais uma de suas principais marcas. Dissemina o obscurantismo cultural e o sectarismo religioso, exalta a negação do conhecimento e da política.

Somente um governo autoritário e subserviente, formado por extremistas de direita, tem a determinação de realizar a ferro e fogo essa agenda ultraliberal, neocolonial, anticivilizacional e anti-humanista. Ao contrário do que quer fazer crer o presidente, o ataque às humanidades nada mais é que a submissão a essa férrea lógica global, de acordo com a qual a cisão do mundo e do ser humano está de uma vez por todas configurada.

As duas faces do ataque às humanidades, a teórica e a política, se relacionam na tentativa de executar uma legislação neocolonial que prevê em seus termos, entre outras coisas, uma perene dependência de ações e conhecimentos formulados nas metrópoles europeias e estadunidense para a resolução dos nossos próprios problemas. Importar tecnologia, know-how, saberes, instituições, cultura e modos de vida, para nos aproximarmos, como sócios menores e cópias imperfeitas, dos centros capitalistas, é a meta e o objetivo da jurisdição neocolonial adotada e aplicada por nosso atual governo federal. 


\section{CONCLUSÃO}

O valor intrínseco às ciências humanas mostra que sua abordagem não pode ser exclusivamente epistemológica, mas essencialmente filosófica. Ao explicitar os pressupostos que agem no momento das escolhas dos objetos e das opções metodológicas, desnaturalizamos as relações histórico-sociais e afastamos a pretensa neutralidade científica. Problematizar filosoficamente o aspecto humanista do conhecimento não é tomá-lo como uma questão para satisfação dos meios imediatos, mas evidenciar a questão da formação das finalidades, dos sentidos das nossas ações coletivas e comunitárias. É justamente em razão da impossibilidade de escapar dos pressupostos filosóficos do compreender histórico-social que é preciso tratar as ciências humanas além dos paradigmas epistemológicos da modernidade.

Os interesses teóricos e políticos neocoloniais se somam para obscurecer a importância fundamental das humanidades, conduzindo a nação a uma subordinação de caráter econômico e político, mas principalmente ideológico. É no domínio das ideias, no amplo espectro da cultura, que se realiza o ápice da dependência e a profunda influência mental sobre o nosso povo e instituições. Ao domínio econômico e político incorpora-se o elemento espiritual, como que forjando as correntes definitivas e as mais pesadas no constrangimento da compreensão e da autonomia do pensamento nacional.

Torna-se necessário, então, resistir de forma ampla e com muita sagacidade política. É preciso radicalizar no conteúdo, pois o autoritarismo da nova elite dirigente é inculto e não sobrevive fora de ambientes obscurantistas. Debates, artigos, formulações e teorias devem ser expostos por professores, intelectuais, artistas, políticos e estudantes. A academia deve se abrir àqueles que querem participar, assumindo a vanguarda contra o irracionalismo e o fundamentalismo religioso.

Por outro lado, também é preciso ampliar as formas de comunicação, dialogando e convencendo outros agentes sociais, principalmente os trabalhadores, dos perigos que essa amálgama entre austeridade econômica, despotismo e obscurantismo representa às suas vidas individual e coletiva. A defesa intransigente da democracia, da liberdade política e do Estado democrático de direito deve ser transformada em bandeira básica contra esse governo com notório arroubo de autoritarismo e tendência fascistizante.

A história nos ensina que, em momentos de crise, a criatividade pode transformar as condições dadas e apresentar saídas. Então, vamos à luta!

* Professor de Filosofia do Colun (Colégio Universitário) da UFMA.

E-mail: capovillacristiano@gmail.com

Texto recebido em março de 2020; aprovado em abril de 2020. 
ABDALLA, Maurício. Em defesa da filosofia. Le Monde Diplomatique Brasil, São Paulo, 14 mar. 2019. Disponível em: <https://diplomatique.org.br/em-defesa-dafilosofia>. Acesso em: 12 dez. 2019.

BOLSONARO, Jair. Brasília, 26 abr. 2019. Twitter: @jairbolsonaro. Disponível em: <https://twitter.com/jairbolsonaro/status/1121713534402990081>. Acesso em: 12 dez. 2019.

BRASIL. Ministério da Educação. Censo da educação superior: notas estatísticas 2017. Brasília, 2017. Disponível em: <http://download.inep.gov.br/educacao superior/censo superior/documentos/2018/censo da educacao superior 2017 notas estatisticas2.pdf>. Acesso em: 12 dez. 2019.

CAPOVILLA, Cristiano. As sociedades de controle: forma hegemônica da acumulação capitalista e padrão de poder da gestão institucional em Gilles Deleuze. Revista Interdisciplinar em Cultura e Sociedade (RICS), São Luís, v. 5, n. 2, p. 262-275, jul./ dez.2019. <http://www.periodicoseletronicos.ufma.br/index.php/ricultsociedade/ article/view/13016/0>.

DOMINGUES, Ivan. Epistemologia das ciências humanas. Tomo I: positivismo e hermenêutica — Durkheim e Weber. São Paulo: Edições Loyola, 2004.

GADAMER, Hans-Georg. Verdade e método I: traços fundamentais de uma hermenêutica filosófica. 11. ed. Petrópolis: Vozes; Bragança Paulista: Editora Universitária São Francisco, 2011.

HEGEL, Georg Wilhelm Friedrich. Fenomenologia do espírito. 6. ed. Petrópolis: Vozes, 2001. v. 1.

JAEGER, Werner. Paideia: a formação do homem grego. 4. ed. São Paulo: Martins Fontes, 2001.

LOSURDO, Domenico. Liberalismo: entre civilização e barbárie. São Paulo: Anita Garibaldi, 2006.

ROLLO, Maria Fernanda. Hobsbawm, "verdadeiramente um grande historiador". Ler História, n. 62, 2012. Disponível em: <http://journals.openedition.org/ lerhistoria/605>. Acesso em: 12 dez. 2019. 